\title{
Editorial
}

\section{The Nurse-Family Partnership: evidence-based public health in response to child maltreatment}

\author{
Lil Tonmyr, PhD, Guest Editor
}

Tweet this article

Too many Canadian children are exposed to child maltreatment-neglect, emotional maltreatment, exposure to intimate partner violence, and physical and sexual abuse. Retrospective data indicates that $32 \%$ of Canadian adults have experienced childhood abuse. ${ }^{1}$ There is evidence that child maltreatment is associated with a wide array of negative health consequences across the life span. These consequences expand across physical, mental, developmental and social domains to include suicide, substance abuse, anxiety, depression and physical health problems. ${ }^{1-4}$

Experts have asked for coordinated national leadership in protecting children from maltreatment. ${ }^{5,6}$ They also envision broadening the mandate for injury prevention to include not only physical injury but also emotional injury and harm.

What can be done to prevent child maltreatment? This section of the special issue of Health Promotion and Chronic Disease Prevention in Canada: Research, Policy and Practice (HPCDP) focusses on prevention strategies for child maltreatment in Canada and, specifically, the Nurse-Family Partnership (NFP). This public health nurse intervention aims to enhance pregnancy outcomes, child health and development, and economic self-sufficiency for the young mothers and children enrolled in the intervention. The NFP, developed in the United States, has shown positive and lasting results in three randomized control trials (RCTs). These results fall in areas relevant to the mandate of the Public Health Agency of Canada:

- reduction in child maltreatment and injuries to children;

- improvement in early childhood mental health and cognitive and language development;

- advances in school readiness;

- decline in adolescent antisocial behaviour;

- enhancement of women's perinatal health;

- increases in maternal economic selfsufficiency; and

- augmentation of fathers' involvement in family-life. ${ }^{7}$

The founder and developer of the program, Dr. David Olds, and his colleagues at the Prevention Research Center at the University of Colorado Denver require a four-step approach before the NFP is implemented in a new society: (1) adaption to a local context (Jack et al. ${ }^{8}$ describe the Canadian adaption in detail); (2) a pilot study to assess acceptability and feasibility in a small sample (the first two steps were implemented in Hamilton, Ontario); (3) an RCT (underway in the British Columbia Healthy Connections Project) to evaluate effectiveness of the intervention; and (4) dissemination and maintenance of the program, if it has proven effective based on the RCT results.

This issue includes four articles related to the NFP intervention program:
- In "Vulnerability within families headed by teen and young adult mothers investigated by child welfare services in Canada,' Hovdestad et al. ${ }^{9}$ show the numerous risk factors experienced by those in this vulnerable population, many of which may be modifiable by programs such as the NFP.

- In "Adapting, piloting and evaluating complex public health interventions: lessons learned from the Nurse-Family Partnership in Canadian public health settings," Jack et al. ${ }^{10}$ describe the process of carefully adapting, assessing and evaluating the feasibility, acceptability and effectiveness of the NFP in Canada to date and the accompanying process evaluation. They also describe an adjunct study that investigates how and if the NFP can reverse biological negative outcomes related to adverse childhood experiences.

- In "Health care and social service professionals' perceptions of a homevisit program for young, first-time mothers," Li et al. ${ }^{11}$ focus on the perspective of the community care providers responsible for referral to the NFP and for delivering services to the mothers. The data are from the Hamilton pilot study. Previous research focussed on the impact of the program on public health nurses $^{12}$ and the experiences of the mothers involved in the program. ${ }^{13}$ Child protection workers are the source of referral for enrolment in the NFP, while the nurses who administer the program are mandated to report to child protection if they suspect child

Author reference:

Surveillance and Epidemiology Division, Public Health Agency of Canada, Ottawa, Ontario, Canada

Correspondence: Lil Tonmyr, Surveillance and Epidemiology Division, Public Health Agency of Canada, 785 Carling Avenue, AL 6807B, Ottawa, ON K1A 0K9; Tel: 613-240-6334; Email: Lil.Tonmyr@phac-aspc.gc.ca 
maltreatment in the families they serve. Collaboration is paramount in this complex relationship.

- In his invited commentary, Dr. Christopher Mikton ${ }^{14}$ of the World Health Organization, writes about Canadian efforts to tackle the "disease" of child maltreatment that affects hundreds of millions worldwide.

We await the outcome of the full evaluation of the NFP program with great interest. If the intervention shows the same effectiveness as it has in the United States, it will provide great hope for Canadian families.

\section{References}

1. Afifi TO, MacMillan HL, Boyle M, Taillieu T, Cheung K, Sareen J. Child abuse and mental disorders in Canada. CMAJ. 2014;186(9): E324-32.

2. Tonmyr L, Jamieson E, Mery LS, MacMillan HL. The relationship between childhood adverse experiences and disability due to physical health problems in a community sample of women. Women Health. 2005; 41(4):23-35.

3. MacMillan HL, Fleming JE, Streiner DL, et al. Childhood abuse and lifetime psychopathology in a community sample. Am J Psychiat. 2001;158(11):1878-83.

4. Rhodes AE, Boyle MH, Bethell J, et al. Child maltreatment and onset of emergency department presentations for suicide-related behaviors. Child Abuse Neg. 2012;36:542-51.

5. MacMillan HL. Protecting children from maltreatment: a Canadian call to action. Paediatr Child Health. 2013;18(8):409.

6. Shouldice M. Child maltreatment in Canada, 2013. Paediatr Child Health. 2013;18(8):407-8.

7. Olds DL, Sadler S, Kitzman H. Programs for parents of infants and toddlers: recent evidence from randomized trials. J Child Psych Psychiatry. 2007;48:355-91.

8. Jack SM, Busser D, Sheehan D, Gonzalez A, Zwygers EJ, MacMillan HL. Adaptation and implementation of the Nurse-Family Partnership in Canada. Can J Public Health. 2012; 103(1):S42-8.
9. Hovdestad W, Shields M, Williams G, Tonmyr L. Vulnerability within families headed by teen and young adult mothers investigated by child welfare services in Canada. Health Promot Chronic Dis Prev Can. 2015;35(8/9):143-50.

10. Jack SM, Catherine N, Gonzalez A, MacMillan HL, Sheean D, Waddell C for the BCHP Scientific Team. Adapting, piloting and evaluating complex health interventions: lessons learned from the NurseFamily Partnership Program in Canadian public health settings. Health Promot Chronic Dis Prev Can. 2015;35(8/9):151-9.

11. Li S-A, Jack SM, Gonzalez A, Duku E, MacMillan HL. Health care and social service professionals' perceptions of a homevisit program for young, first-time mothers. Health Promot Chronic Dis Prev Can. 2015;35(8/9):160-7.

12. Dmytryshyn AL, Jack SM, Ballantyne M, Wahoush O, MacMillan HL. Long-term home visiting with vulnerable young mothers: an interpretive description of the implication public health nurses. BMC Nurs. 2015;14:12.

13. Landy CK, Jack SM, Wahoush O, Sheehan D, MacMillan HL; NFP Hamilton Research Team. Mothers' experiences in the NurseFamily Partnership program: a qualitative case study. BMC Nurs. 2012;11:15.

14. Mikton C. Commentary. Adapting and retesting evidence-based child maltreatment prevention programs: a case study in Canada. Health Promot Chronic Dis Prev Can. 2015;35(8/9):168-70. 